\title{
Assessment of patients with multiple sclerosis according to tests of the Multiple Sclerosis Functional Composite
}

\author{
Avaliação de pacientes com esclerose múltipla segundo \\ testes da Multiple Sclerosis Functional Composite
}

\author{
Anelise Ineu Figueiredo ${ }^{[a]}$, Carla Roberta Nunes Polachini ${ }^{[b]}$, Ana Lucia Cervi Prado ${ }^{[b]^{*}}$ \\ [a] Centro Universitário Metodista IPA, Porto Alegre, RS, Brazil \\ [b] Universidade Federal de Santa Maria (UFSM), Santa Maria, RS, Brazil
}

\begin{abstract}
Introduction: The Multiple Sclerosis Functional Composite (MSFC) is a scale that evaluates the functional and cognitive aspects of patients with multiple sclerosis (MS). Objective: To compare the performance of individuals with the relapsing-remitting form of MS (RRMS) with a group of healthy subjects using the MSFC. Methods: Twenty subjects were investigated in this study, consisting of 10 patients with clinical diagnosis of RRMS and 10 controls with similar gender and age to the group with the disease. The three tests that comprise the MSFC were used for the evaluation of gait, upper limb motor function and cognition (memory and processing speed). Student's t-test was used to assess data with normal distribution and data with skewed distribution were evaluated using the Mann-Whitney test. Results: The results showed that the patients with RRMS took longer to perform the locomotion test $(6.91 \pm 2.35)$ compared to the control group (5.16 \pm 1.28). The MS group (22.06 \pm 5.44$)$ also showed greater difficulty in performing a task with the dominant upper limb compared to the healthy subjects $(17.79 \pm 2.96)$. No statistically significant difference was found between the groups in the performance of cognitive tasks $(p=.65)$. Conclusion: The use of the MSFC tests proved valuable for measuring possible motor and cognitive impairments in patients with RRMS. Thus, it is
\end{abstract}

*AIF: MS, e-mail: aneliseif@gmail.com

CRNP: Doctoral Student, e-mail: carlinha_polachini@hotmail.com

ALCP: PhD, e-mail: analucia459@hotmail.com

Fisioter Mov. 2016 Oct/Dec;29(4):677-84 
suggested that this scale is adopted in clinical practice, improving therapies for the treatment of MS patients and thereby providing them a better quality of life.

Keywords: Multiple Sclerosis. Measures. Motor Skills. Cognition.

\section{Resumo}

Introdução: A Multiple Sclerosis Functional Composite (MSFC) é uma escala que avalia aspectos funcionais e cognitivos em pacientes com esclerose múltipla (EM). Objetivo: Comparar o desempenho de indivíduos com a forma surto-remissão de EM (SREM) com um grupo de sujeitos saudáveis utilizando a MSFC. Métodos: Vinte sujeitos foram investigados no presente estudo, desses 10 eram pacientes com diagnóstico clínico SREM e 10 controles com sexo e idade semelhantes ao grupo com a doença. Foram utilizados os três testes que compõem a MSFC para avaliação da marcha, função motora de membros superiores e cognição (memória e velocidade de processamento). Para aferir os dados com distribuição normal utilizou-se o teste t de Student e os dados com distribuição assimétrica foram avaliados pelo Teste de Mann-Whitney. Resultados: Os pacientes com SREM apresentaram um tempo maior para realizar o teste de locomoção $(6,91 \pm 2,35)$ quando comparado ao grupo controle $(5,16 \pm 1,28)$. Além disso, o grupo com EM $(22,06 \pm 5,44)$ também demonstrou maior dificuldade em realizar uma tarefa com o membro superior dominante em relação aos indivíduos saudáveis $(17,79 \pm 2,96)$. Entretanto, não foi encontrada diferença estatisticamente significativa entre os grupos na execução das atividades cognitivas $(P=0,65)$. Conclusão: A aplicação dos testes da MSFC mostrou-se de grande valia para mensurar possíveis comprometimentos motores e cognitivos de pacientes com SREM. Assim, sugere-se que esta escala seja adotada na prática clínica, aprimorando terapias de tratamento dos portadores de EM e desse modo, proporcionando-lhes uma melhor qualidade de vida.

Palavras-chave: Esclerose Múltipla. Medidas. Habilidades Motoras. Cognição.

\section{Introduction}

Multiple sclerosis (MS) is an inflammatory autoimmune disease characterized by demyelinating lesions in the central nervous system (CNS), which has a slow and progressive course with periods of remission and exacerbation of the neurologic symptoms $(1,2)$. It can affect motor, sensory, cerebellar, cognitive, sphincter and spinal cord areas (3).

Multiple sclerosis predominates in young adults, affecting them in the productive phase of their professional life, with the incidence being higher in females and it often being a disabling disease $(4,5)$. Studies show that in Brazil, the prevalence is 15 cases per 100 thousand inhabitants, being more frequent in the south and southeast of the country $(6,7)$.

According to the symptomatology and clinical findings, there are four subtypes of MS: relapsing-remitting, secondary-progressive, primary-progressive and progressive-relapsing (8). The relapsing-remitting form is present in about $80 \%$ of cases, characterized by relapses with new or worsening of symptoms, interspersed with periods of complete or partial remission of symptoms between the relapses (9).
Normally, this disease starts as a relapsing-remitting process and evolves into a secondary-progressive phase with the accumulation of disabilities (10). In the remaining cases, it assumes a progressive form from the beginning, with these patients presenting a progressive course of disabilities (11).

Although the etiology of MS remains unknown, currently, it is believed there is an influence from immune, genetic and environmental factors (12). Due to the diffuse character of the formation of the demyelinating plaques, the clinical manifestations are determined by the location of the lesions and are highly variable, including gait and sensory disturbances, spasticity, visual deficits, fatigue, bladder disorders, motor incoordination, and cognitive changes, such as slower information processing (13). Thus, these changes may limit people with MS in the performance of their daily activities, as well as remove them from social life $(14,15)$.

The therapy used is individualized, with this having different objectives, dependent upon the clinical signs presented by each patient. Pharmacological treatment is accomplished through the use of anti-inflammatory, immunomodulatory and immunosuppressive medications (16). In addition, multidisciplinary rehabilitation 
programs also represent an important non-pharmacological approach used with these patients (17). This multidisciplinary treatment aims to improve the performance of people with MS in their activities of daily living (ADLs), to maximize functional abilities, as well as to prevent the onset of disability, thus improving their quality of life (18).

The instruments available to conduct clinical evaluations present a constant challenge due to the large variability between periods of disability and improvement of the symptoms that this disease causes, making it difficult to quantify them in the neurology practice (19). Thus, some neurological scales, such as: the Expanded Disability Status Scale (EDSS) and the Ambulatory Index (AI) have been used to verify the changes that MS patients present. However, these scales have many problems and limitations, including: the fact that they are long for clinical application, have ordinal and not interval measures and the areas evaluated emphasize aspects related to physical disabilities, ignoring cognitive functioning (20).

In an attempt to accompany the evolution of the clinical condition in a simplified and standardized way, the National Multiple Sclerosis Society (NMSS) of the USA developed a scale known as: the Multiple Sclerosis Functional Composite (MSFC) which measures the main disabilities found in patients with MS in a multidimensional way (21). The MSFC evaluates ambulation, upper limb function and cognitive aspects through tests encompassing the three main domains affections by this disease $(22,23)$. Thus, this scale has been considered superior to others, due to its ease of application and the reliability of the results obtained (24).

In the search for alternatives to assess the main deficits and the evolution of the condition of patients with MS, this study aimed to compare the performance of individuals with the relapsing-remitting form of multiple sclerosis with healthy subjects in the functional and cognitive tasks required by the MSFC, seeking, through these tests, to find the main neurological compromises of MS patients in the remission phase.

\section{Methods}

\section{- Study design}

This study was characterized as a prospective, cross-sectional study, with quantitative data analysis.

\section{- Ethical aspects}

The evaluation methods and intervention protocols used in this study are in accordance with the requirements of Resolution No. 196/96 of the National Health Council on research involving human subjects and were approved by the Research Ethics Committee of the Federal University of Santa Maria under authorization No. 00731012.5.0000.5346. All participants voluntarily signed the Informed Consent form prior to performing the tests, with it being clear that they could withdraw from participation at any time, without prejudice.

- Subjects

The sample consisted of 20 individuals. The initial group consisted of 15 patients with MS, however, 5 were excluded because they did not meet the inclusion criteria. Individuals who were clinically diagnosed as being in the progressive phase of the disease were excluded from the study. The subjects with the disease included in the study had to be able to move around by walking, have comprehensive language and have no visual impairment that would prevent the tests, all patients had to be in the remission phase. Thus, 10 patients with clinical diagnosis of relapsingremitting type Multiple Sclerosis from the rehabilitation program of the University Hospital of Santa Maria/RS Physiotherapy Service, in the period June to September 2012, and 10 healthy volunteers, as the control group, were selected for this study.

Participants were divided into two groups: the MS Group: composed of patients with the relapsingremitting form of the disease, of both genders, aged 12 to 50 and the Control Group: composed of healthy volunteers, with genders and ages the same or similar to the MS group.

\section{- Experimental procedure}

Prior to testing, the participants answered some questions regarding: the stage of the disease, its onset, frequency of relapses, main symptoms, use of pharmacological therapy and of other forms of treatment therapies. Next, the Multiple Sclerosis Functional Composite Measure (MSFC) was applied, which consists of three tests: Timed 25-Foot Walk, 9-Hole Peg Test and Paced Auditory Serial Addition Task $(25,26,19)$. 
For the evaluation of the gait, the Timed 25-Foot Walk was used, a test that consists of a mark at a distance of 7.62 meters ( 25 feet), each 1 foot $=30.48$ $\mathrm{cm}$, with the individual being encouraged to walk as fast as he/she could without running, over two attempts. A stopwatch is used to measure the time, which is expressed in tenths of a second, this task was carried out in the corridor of the University Hospital of Santa Maria (HUSM) Physiotherapy Service.

Subsequently, the 9-Hole Peg Test was applied, which assesses the motor function of the upper limbs. For the performance of this test a wooden kit was made in the carpentry workshop of the UFSM Arts Center, which consists of a board with nine holes in which nine pins can be inserted, one by one. On the side of the board there is a space to store all the pins at the beginning and end of the evaluation. The place where the pins are stored faces the hand that will be tested, with the row of holes facing the hand that is not being tested. Primarily, two evaluations are performed with the dominant hand and then two evaluations with the non-dominant hand. The participant is encouraged to put the pins in the holes as fast as possible, with the timer being started when the first pin is taken. Each pin should be placed in a hole in any order and then each pin is returned, one by one, to the place where they are stored, whereupon the clock is stopped.

Finally, the Paced Auditory Serial Addition Task (PASAT) was applied, which verifies the cognitive impairment and involves memory and processing speed tasks. In this scale, this test is applied twice, first with intervals of 3 seconds between the stimuli and secondly with intervals of 2 seconds. The stimuli were given by the researcher in a loud and clear voice. Numbers from one to nine are presented in a random and pre-determined sequence. The task is to sum the numbers presented, in pairs, disregarding the result of the calculation, therefore, if the string is " $4,3,6,2$ and 1 " the correct answer is " $7,9,8$ and 3 ". The test was administered in a quiet room without visual or auditory stimuli, with only the subject and the examiner present in the room. At first a version with 10 items for training was presented. When the participant demonstrated difficulty in understanding, a demonstration in writing was performed with the series of number.

-Statistical analysis

The GraphPad Prism software was used. Data are expressed as mean \pm standard deviation (SD) or median and interquartile range (p 25 - 75). Data with normal distribution were analyzed using the paired Student's t-test and those with asymmetric distribution were analyzed using the Mann-Whitney test. All results were considered significant when $p<.05$

\section{Results}

Table 1 presents the general characteristics of the subjects with MS. It was observed that MS predominantly affected females between the aged of 13 and 50 years. The majority of the patients had a mean of 3 relapses per year, had the diagnosis for a mean of $6.2 \pm 4.0$ years, with the use of glatiramer acetate being prevalent for the treatment in this population.

Table $\mathbf{1}$ - General characteristics of the study participants

\begin{tabular}{lcc}
\hline & Patients with MS & Control subjects \\
\hline $\mathrm{N}$ & 10 & 10 \\
Women & 2 & 7 \\
Men & & 3 \\
$\begin{array}{l}\text { Age (mean and } \\
\text { range) }\end{array}$ & $40.4 \pm 13.1,13-50$ & $41.2 \pm 13.8,13-53$ \\
$\begin{array}{l}\text { Relapses (per year) } \\
\text { Duration of disease } \\
\text { (years) }\end{array}$ & $3.1 \pm 1.66$ & - \\
$\begin{array}{l}\text { Use of glatiramer } \\
\text { acetate (n) }\end{array}$ & $6.2 \pm 4.0$ & - \\
$\begin{array}{l}\text { Use of Interferon } \\
\boldsymbol{\beta} \text { (n) }\end{array}$ & 6 & - \\
\hline
\end{tabular}

Note: The variables, such as age, number of yearly relapses and duration of disease are presented as mean \pm SD.

The results of the gait assessment test revealed that the MS group presented significant impairment in locomotion $(6.91 \pm 2.35, p<.05)$ compared to the control group $(5.16 \pm 1.28, p<.05)$ (Figure 1). Importantly, there was no significant difference for the people with MS when comparing the locomotion times of the first and the second attempt ( $p=.73)$. 


\section{5- FW}

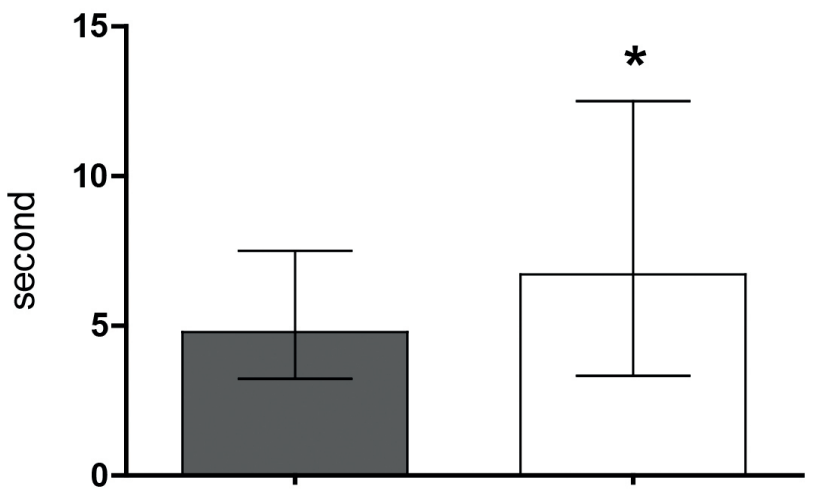

Figure 1 - Timed 25-Foot Walk for the MS and control groups. Values represented in median with interquartile range (P25-P75). *represents a significant difference from the control group (MannWhitney test, $p<.05 \mathrm{n}=10$ ).

Regarding the upper limbs test, a significant decline in function was observed in the MS group, as these patients took longer to perform the task with the dominant upper limb (22.06 \pm 5.44$)$ compared to the control group $(17.79 \pm 2.96)$ (Figure 2).

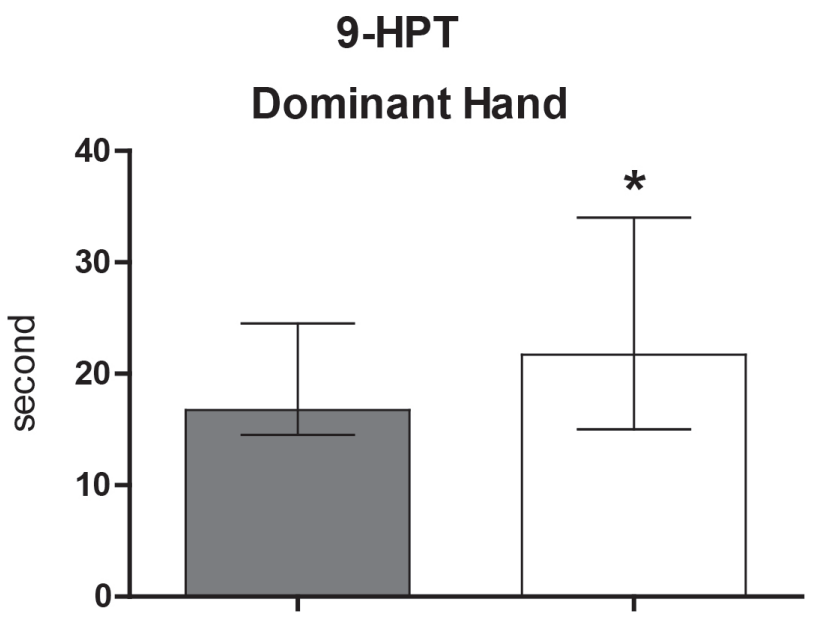

Figure 2 - 9-Hole Peg Test for the MS and control groups. Values represented in median with interquartile range (P25 - P75). *represents a significant difference from the control group (Mann-Whitney test, $P<.05 n=10$ ).

Figure 3 shows the results of the test that assessed the memory and cognition of the participants. As can be observed, there was no significant difference after a 3 second interval ( $p=.75$ ) (3a), nor in the performance of the test after 2 seconds ( $p=.23$ ) (3b), between the MS patients and the healthy individuals. Furthermore, it is important to note that some patients were only able to carry out the first stage of the test, in which an interval of 3 seconds is given between the stimuli. When summing of the number of correct responses in the 3" and 2" tests, no significant difference was detected between the study participants ( $p=.65$ ) (3c).

3a.

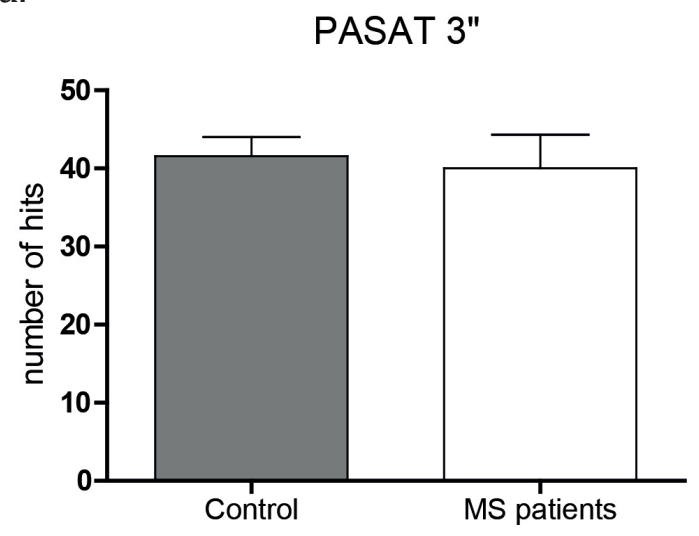

$3 b$.

\section{PASAT 2"}

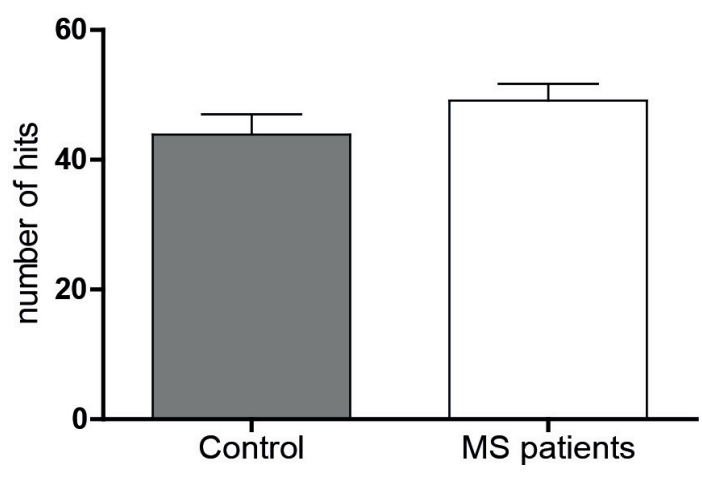

3c.

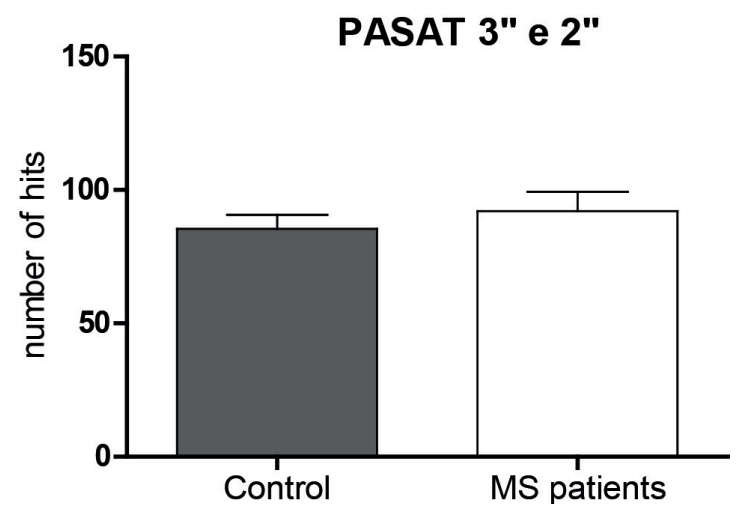

Figure 3 - Paced Auditory Serial Addition Task: 3" (a) 2" (b) 3" and 2" (c) for the MS and control groups. Values represented as mean \pm SD. (Student's t-test, $p<.05 n=10$ and $n=7$, respectively). 


\section{Discussion}

This study aimed to investigate the functionality and cognitive performance of MS patients, through the MSFC test, and to compare their performance with a group of healthy subjects. Even though the sample to which the tests of this scale were applied was small, it was found that the patients with RRMS presented deficits in gait and upper limb motor function when compared to the control group. However, both groups showed the same performance in the cognitive function test.

In this study $80 \%$ of the sample consisted of women with a mean age of 40 years. These data corroborate the reports in the literature that show multiple sclerosis presents in higher proportions among women $(27,28)$, at around 40 years of age $(29)$. In addition, there are a large number of studies showing that the relapsing-remitting form is the most prevalent form (30), consequently, all the patients in this study were in this phase, characterized by complete recovery of symptoms, however, in some cases leaving residual sequelae (31).

Among the key findings, it should be noted that the MS group needed more time to perform the walking test, Timed 25-Foot Walk, when compared with the control group. This behavior shows that, even in a symptom remission phase, patients present impairment in the gait. This difficulty in the individuals with MS may have been due to fatigue, muscle weakness and/or spasticity, or a combination of these factors. It is suggested that being slower to complete the proposed test might be due to some post-relapse residual deficit.

Fatigue may have been the main cause of the decline in the function of the lower limbs, considering that it is one of the most common and disabling symptoms in MS, affecting about 50 to $60 \%$ of patients (32). It is regarded as the most disabling symptom, when compared to spasticity and muscle weakness (33). According to Mendes et al. (34) in patients with neurological diseases, fatigue is different from that reported in other diseases, because in these cases it leads to greater impairment of the quality of life, causing difficulty in the performance of work activities and eventually leading to social isolation, with this symptom being very relevant to the general condition of the patients. These authors also claim that, in MS this feeling of fatigue is often associated with a degree of persistent disability and, although it is chronic, the fatigue fluctuates in intensity, being more intense in the late afternoon and at elevated temperatures (34).

Importantly, in patients with MS the fatigue that arises is possibly of multifactorial origin (central and/or peripheral) and is related to immune and central changes, inability to maintain a central impulse for spinal motor neurons due to demyelination, lack of physical conditioning and changes in the neuromuscular plate (35). In addition, in studies conducted by Solari et al. (36) it was observed that people with MS presented difficulties in the learning process to carry out the task required in the Timed 25-Foot Walk, therefore, this may be an effective test to monitor the progress of patients, since the results of the present study show that in the relapsing-remitting phase there is already a significant reduction in the walking speed of MS patients when compared with healthy subjects.

In this study it was also observed that MS patients required a longer time to perform the upper limb functional test compared to the control group. This result may be due to the presence of demyelinating plaques in the cerebellum, which leads to a decrease in motor function resulting in difficulty to perform tasks that require more manual dexterity. The motor deficit may impair the performance of movements of the upper members and hinder the execution of fine motor skills (37).

Regarding cognition, the results of this study showed no significant difference between the groups in the test that evaluated this parameter. The failure to find a significant difference between the groups may suggest that the scale used is sensitive to the location of the demyelinating plaques, and that the evaluated subjects had greater impairment at the spinal cord level. Corroborating this hypothesis, Moreira et al. (38) found in their study that the most common evolutionary symptoms in the relapsing-remitting form were spinal cord symptoms (75.9\%). In addition, many MS patients tend to present more cognitive deterioration when they are in the progressive phase of the disease (39).

\section{Conclusion}

Based on the results obtained in this study, it was concluded that MSFC was sensitive to evaluate the functional performance in subjects with the relapsing-remitting form of MS when compared with 
healthy subjects. Regarding the cognitive aspect, in addition to the tasks involving memory and processing speed, it is believed that other tests should be added to better assess this parameter. However, the MSFC, due to its ease of application, can be replicated and used in the clinic to monitor the progress of the disease, thus prioritizing the individual needs of each patient and optimizing the treatment proposals.

\section{References}

1. Compston A, Coles A. Multiple sclerosis. Lancet. 2002;359(9313):1221-31.

2. Confavreux C, Vukusic S. Multiple sclerosis: a degenerative disease? Bull Acad Natl Med. 2008;192(3):483-91.

3. Kantarci $\mathrm{OH}$, Weinshenker BG. Natural history of multiple sclerosis. Neurol Clin. 2005;23(1):17-38.

4. Trojano M, Lucchese G, Graziano G, Taylor BV, Simpson Jr S, Lepore V, et al. Geographical variations in sex ratio trends over time in multiple sclerosis. PLoS One. 2012;7(10):e48078.

5. Nogueira LA, Nóbrega FR, Lopes KN, Thuler LC, Alvarenga RM. The effect of functional limitations and fatigue on the quality of life in people with multiple sclerosis. Arq Neuropsiquiatr. 2009;67(3B):812-7.

6. Finkelsztejn A, Cristovam RA, Moraes GS, Lopes MG, Silva AV, Garcia MS, et al. Clinical features of multiple sclerosis in the south of Brazil. Arq Neuropsiquiatr. 2009;67(4):1071-5.

7. Cardoso E, Fukuda T, Pereira J, Seixas J, Miranda $\mathrm{R}$, Rodrigues $\mathrm{B}$, et al. Clinical and epidemiological profile of multiple sclerosis in a reference center in the State of Bahia, Brazil. Arq Neuropsiquiatr. 2006;64(3B):727-30.

8. Negreiros MA, Fernandez JL, Kirchmeyer CV, Paes RA, Alvarenga R, Mattos P. Alterações cognitivas em indivíduos brasileiros com esclerose múltipla surtoremissão. J Bras Psiquiatr. 2011;60(4):266-76.

9. Reipert, B. Multiple sclerosis: a short review of the disease and its differences between men and woman. J Mens Health Gend. 2004;1(4):334-40.
10. Ortiz GG, Pacheco-Moisés FP, Bitzer-Quintero OK, Ramírez-Anguiano AC, Flores-Alvarado LJ, RamírezRamírez V, et al. Immunology and Oxidative Stress in Multiple Sclerosis: Clinical and Basic Approach. Clin Dev Immunol. 2013;2013:708659.

11. Noseworthy JH, Lucchinetti C, Rodriguez M, Weinshenker BG. Multiple sclerosis. N Engl J Med. 2000;343(13):938-52.

12. Compston A, Coles A. Multiple sclerosis. Lancet. 2008;372(9648):1502-17.

13. Costello K. Multiple sclerosis research: diagnostics, disease-modifying treatments, and emerging therapies. J Neurosci Nurs. 2013;45(6 Suppl 1):S14-23.

14. Mitchell AJ, Benito-León J, González JM, Rivera-Navarro J. Quality of life and its assessment in multiple sclerosis: integrating physical and psychological components of wellbeing. Lancet Neurol. 2005;4(9):556-66.

15. Overs S, Hughes CM, Haselkorn JK, Turner AP. Modifiable comorbidities and disability in multiple sclerosis. Curr Neurol Neurosci Rep. 2012;12(5):610-7.

16. Goodin DS, Frohman EM, Garmany Jr GP, Halper J, Likosky WH, Lublin FD, et al. Disease modifying therapies in multiple sclerosis: report of the Therapeutics and Technology Assessment Subcommittee of the American Academy of Neurology and the MS Council for Clinical Practice Guidelines. Neurology. 2002;58(2):169-78.

17. Khan F, Turner-Stokes L, Ng L, Kilpatrick T. Multidisciplinary rehabilitation for adults with multiple sclerosis. J Neurol Neurosurg Psychiatry. 2008;79(2):114.

18. Liberatore G, Clarelli F, Nuara A, Ungaro D, Gatti R, Rovaris M, et al. Predictors of effectiveness of multidisciplinary rehabilitation treatment on motor dysfunction in multiple sclerosis. Mult Scler. 2013;20:862-70.

19. Tilbery CP, Mendes MF, Thomaz RB, Oliveira BE, Kelian GL, Busch R, et al. Multiple Sclerosis Functional Composite Measure (MSFC) standardized in the Brazilian population. Arq Neuropsiquiatr. 2005;63(1):127-32.

20. Haase VG, Lima EP, Lacerda SS, Lana-Peixoto MA. Desenvolvimento da Versão Brasileira da Multiple Sclerosis Funcional Composite Measure (MSFC - BCTRIMS). Arq Neuropsiquiatr. 2004;62(2):363-70. 
21. Cutter GR, Baier ML, Rudick RA, Cookfair DL, Fischer JS, Petkau J, et al. Development of a multiple sclerosis functional composite as a clinical trial outcome measure. Brain 1999;122(Pt 5):871-82.

22. Cohen JA, Fischer JS, Bolibrush DM, Jak AJ, Kniker JE, Mertz LA, et al. Intrarater and interrater reliability of the MS functional composite outcome measure. Neurology. 2000;54(4):802-6.

23. Hofstetter L, Naegelin Y, Filli L, Kuster P, Traud $\mathrm{S}$, Smieskova R, et al. Progression in disability and regional grey matter atrophy in relapsing-remitting multiple sclerosis. Mult Scler. 2013;20(2):202-13.

24. Drake AS, Weinstock-Guttman B, Morrow SA, Hojnacki D, Munschauer FE, Benedict RH. Psychometrics and normative data for the Multiple Sclerosis Functional Composite: replacing the PASAT with the Symbol Digit Modalities Test. Mult Scler. 2010;16(2):228-37.

25. Cohen JA, Cutter GR, Fischer JS, Goodman AD, Heidenreich $\mathrm{FR}$, Jak AJ, et al. Use of the multiple sclerosis functional composite as an outcome measure in a phase 3 clinical trial. Arch Neurol. 2001;58(6):961-7.

26. Fischer JS, Jak AJ, Kniker JE, Rudick RA, Cutter G. Administration and scoring manual for the Multiple Sclerosis Functional Composite Measure (MSFC) - Revised Oct 2001. New York: National Multiple Sclerosis Society; 2001: 1-40.

27. Magyari M, Koch-Henriksen N, Pfleger CC, Sørensen PS. Reproduction and the risk of multiple sclerosis. Mult Scler. 2013;19(12):1604-9.

28. Nielsen NM, Jørgensen KT, Stenager E, Jensen A, Pedersen BV, Hjalgrim $\mathrm{H}$, et al. Reproductive history and risk of multiple sclerosis. Epidemiology. 2011;22(4):546-52.

29. Koch-Henriksen N, Sorensen PS. Why does the northsouth gradient of incidence of multiple sclerosis seem to have disappeared on the Northern hemisphere? J Neurol Sci. 2011;311(1-2):58-63.

30. Wakerley B, Nicholas R, Malik O. Multiple Sclerosis. Medicine. 2008;36(12):625-9.

31. Murray TJ. Diagnosis and treatment of multiple sclerosis. BMJ. 2006;332(7540): 525-7.

32. Amato MP, Portaccio E. Management options in multiple sclerosis-associated fatigue. Expert Opin Pharmacother. 2012;13(2):207-16.
33. Kluger BM, Krupp LB, Enoka RM. Fatigue and fatigability in neurologic illnesses: proposal for a unified taxonomy. Neurology. 2013;80(4):409-16.

34. Mendes MF, TilberyCP, Balsimelli S, Felipe E, Moreira MA, Barão-Cruz AM. Fadiga na forma remitente recorrente da Esclerose Múltipla. Arq Neuropsiquiatr. 2000;58(2-B):471-5.

35. Pavan K, Schmidt K, Ariça TA, Mendes MF, Tilbery CP, Lianza S. Avaliação da fatigabilidade em pacientes com esclerose múltipla através do dinamômetro manual. Arq Neuropsiquiatr. 2006;64(2-A):283-6.

36. Solari A, Radice D, Manneschi L, Motti L, Montanari E. The multiple sclerosis functional composite: different practice effects in the three test components. J Neurol Sci. 2005;228(1):71-4.

37. Cardoso FAG. Atuação fisioterapêutica na esclerose múltipla forma recorrente-remitente. Movimenta. 2010;3(2):69-75.

38. Moreira MA, Felipe E, Mendes MF, Tilbery CP. Esclerose Múltipla: Estudo descritivo de suas formas clínicas em 302 casos. Arq Neuropsiquiatr. 2000;58(2-B):460-6.

39. Huijbregts SC, Kalkers NF, de Sonneville LM, de Groot V, Reuling IE, Polman CH. Differences in cognitive impairment of relapsing remitting, secondary, and primary progressive MS. Neurology. 2004;63(2):335-9.

Received in $01 / 15 / 2015$

Recebido em 15/01/2015

Approved in 11/12/2015

Aprovado em 12/11/2015 